\title{
Representações na aprendizagem da derivada de uma função por alunos do ensino secundário
}

\author{
Representations in the learning of the derivative of a function by secondary school \\ students
}

Floriano Viseu ${ }^{1}$

\begin{abstract}
Resumo
Este estudo tem como objetivo averiguar o contributo das representações na aprendizagem da derivada de uma função de alunos do 11. ${ }^{\circ}$ ano. Adotando uma abordagem qualitativa e interpretativa, recolheram-se os dados através das resoluções de tarefas realizadas pelos alunos. Os resultados apontam que, apesar da tendência para a representação algébrica, as representações numérica, tabelar e gráfica também foram usadas. A representação numérica e a algébrica foram usadas essencialmente para determinar a imagem de um dado objeto, em particular, no caso de extremos relativos. A representação gráfica foi utilizada no estudo comparativo da função com a sua função derivada ou sempre que os alunos pretendiam uma imagem global do comportamento da função. A representação tabelar foi usada essencialmente para estudar a monotonia e os extremos relativos de uma função, e, em alguns casos, na conversão entre a representação algébrica e gráfica.
\end{abstract}

Palavras-chave: Aprendizagem da derivada de uma função; Representações; Alunos do ensino secundário.

\begin{abstract}
The main goal of this study is to verify the contribution that representations give to the learning of the derivate of a function by 11th grade students. Adopting a qualitative and interpretative approach, the data was collected through the students' resolution of tasks. The results indicate that, in spite generalized use of the algebraic representation, the numerical, the tabular, and the graphic representations were also used. The numerical and algebraic representations were used essentially to determine the image of a given object, in particular, in the case of relative extremes. The graphic representation was used to compare a function with its derivate function or whenever the students wanted a global image of the function behaviour. The tabular representation was used essentially to study the monotony and the relative extremes of a function and, in some cases, in the conversion between the algebraic and the graphic representation.
\end{abstract}

Keywords: Learning of the derivate of a function; Representations; secondary school students.

\section{Introdução}

Este estudo incide sobre o ensino e a aprendizagem do tema derivada de uma função numa turma de Matemática $\mathrm{A}^{2}$ do $11 .^{\circ}$ ano de escolaridade do curso de Ciências e Tecnologias, com recurso à conexão entre as diferentes representações de conceitos deste

\footnotetext{
${ }^{1}$ Doutor em Educação, Especialidade de Didática da Matemática, pela Universidade de Lisboa. Professor do Instituto de Educação da Universidade do Minho, Portugal. E-mail: fviseu@ie.uminho.pt.

${ }^{2} \mathrm{O}$ sistema de ensino português engloba 12 anos antes da entrada no ensino superior, assim como a generalidade dos países do mundo. Desses anos, os primeiros nove correspondem ao ensino básico e os três últimos ao ensino secundário. No ensino básico (formado por três ciclos: o primeiro de quatro anos, e com professor único, o segundo de dois anos, e o terceiro ciclo de três anos), o currículo da disciplina de Matemática é igual para todos os alunos. Nos tês anos de ensino secundário, no qual os alunos começam a ser encaminhados para um grupo de cursos do ensino superior, os currículos da disciplina de Matemática divergem, de acordo com os cursos de Ciências, Humanísticos, Tecnológicos ou de Artes.
}

Zetetiké, Campinas, SP, v.25, n.2, maio./ago.2017, p.265-288.

ISSN 2176-1744 
DOI: http://dx.doi.org/10.20396/zet.v25i2.8649274

tema, à calculadora gráfica e a estratégias de ensino que apelaram à intuição e à observação gráfica. Como defendem Teixeira, Precatado, Albuquerque, Antunes e Nápoles (1998), “o estudo das funções (...) deve ser feito colocando em primeiro plano abordagens gráficas e intuitivas e relacionando de forma sistemática abordagens gráficas e analíticas" (p. 8). Trata-se de um tema que é contemplado pelas sucessivas reformas curriculares de Matemática no ensino secundário e cujas orientações metodológicas têm vindo a valorizar um ensino que explore materiais tecnológicos que promovam e possibilitem a utilização das várias representações de um mesmo conceito, em detrimento de um ensino predominantemente analítico. Diversos autores advogam a importância do recurso às várias representações no estudo de conceitos de derivada de uma função para a sua compreensão, tais como Azcárate, Casadevall, Casellas e Bosch (1996), Dreyfus (2002), Duval (2012), Ferri-Mundy e Graham (1993), Ferri-Mundy e Lauten (1994), Ruthven (1993) e Tall (1994). Como se trata de um tema que é iniciado no $11 .^{\circ}$ ano de escolaridade, ganha relevância que a introdução e a sistematização dos seus conceitos atendam à conexão entre as diferentes representações. Por exemplo, no ensino do conceito de derivada, se os alunos tiverem a oportunidade de explorar e sintetizar as relações que existem entre a informação analítica e gráfica desenvolvem uma compreensão mais rica do conceito do que se trabalharem somente com processos analíticos (Dreyfus, 2002). A visualização da representação gráfica potencia a compreensão de conceitos matemáticos (Azcárate et al., 1996; Dreyfus, 2002; Tall, 2002). As recomendações do NCTM (2008) são no sentido de privilegiar os aspetos intuitivos e relacionais a partir da representação gráfica, em que a intuição, segundo Tall (2002), é vista como "o produto das imagens mentais do indivíduo" (p. 14).

Com os recursos tecnológicos que estão à disposição dos alunos e do professor, a exploração das diversas representações de um conceito matemático torna-se mais acessível (Dick, 1996). Entre os recursos tecnológicos a utilizar no estudo da derivada de uma função destaca-se a calculadora gráfica por possuir as desejadas capacidades computacionais e porque, atualmente, a maior parte dos alunos portugueses do ensino secundário possui uma, o que lhes permite resolver individualmente as tarefas propostas e "construírem um conhecimento mais rico do conceito de derivada com recurso às conexões entre as três representações [algébrica, gráfica e numérica]" (Dick, 1996, p. 45). A valorização que as recomendações atuais da educação matemática dão à utilização das diferentes representações para o ensino de conceitos matemáticos levou a averiguar o seu contributo na aprendizagem de tópicos de derivada de uma função.

\section{O ensino das derivadas no ensino secundário}

A introdução das derivadas no programa do Ensino Secundário de Portugal, ocorreu em 1905 na 7. ${ }^{\text {a }}$ classe do curso complementar de Ciências no capítulo destinado à Álgebra. Desde a sua introdução "no plano de estudo do ensino liceal, no ano de 1905 até ao final do século XX, com exceção da reforma (...) em 1936, em que aquela foi suprimida, assistimos a uma afirmação e aumento do espaço dedicado" (Aires \& Vazquez, 2004, p. 120). As aplicações das derivadas apenas começaram a fazer parte do currículo escolar a partir da 
DOI: http://dx.doi.org/10.20396/zet.v25i2.8649274

reforma de 1954 mantendo-se até aos dias de hoje. Atualmente, o tema derivada de uma função faz parte dos programas dos $11 .^{\circ}$ e $12 .^{\circ}$ anos de escolaridade. No que diz respeito ao 11..$^{\circ}$ ano, o tema das funções tem como um dos objetivos introduzir tópicos do cálculo diferencial. Esta introdução inicia-se, analiticamente, com a definição de derivada de uma função num dado valor do seu domínio - como sendo o limite da razão incremental na vizinhança desse valor -, o que geometricamente é associado ao declive da reta tangente ao gráfico da função no ponto que tem de abcissa tal valor (Portugal, 2014). Na fase seguinte à definição de derivada, o programa sugere a aplicação desta noção à cinemática do ponto, o estudo das operações com derivadas pela definição e pela aplicação de regras de derivação de algumas funções simples, a aplicação da noção de derivada ao estudo de funções e a resolução de problemas de otimização.

No processo de ensino e aprendizagem de matemática, dependendo da tarefa ou do conceito em estudo, são utilizadas as representações algébricas, numéricas, tabelares e gráficas das funções. Para cada uma dessas representações existem diferentes vantagens em termos de compreensão e aplicação dos conceitos (Friedlander \& Tabach, 2001; Tall, 2002). Dreyfus (2002) considera que o sucesso na disciplina de Matemática depende da riqueza das representações mentais dos conceitos matemáticos, ao defender que "uma representação é rica se contém o maior número de conexões das propriedades do conceito” (p. 32). A aquisição de flexibilidade no tratamento das diferentes representações dos conceitos do cálculo diferencial é um passo necessário para a introdução posterior do cálculo formal, assegurando uma sólida base para compreender os conceitos e métodos cada vez mais abstratos, que se constroem a partir do $11 .^{\circ}$ ano de escolaridade. Apesar das representações terem um papel importante na Matemática, os alunos tendem a confiar mais na manipulação de expressões analíticas do que na utilização da visualização, restringindo, por vezes, o seu pensamento apenas a uma representação sem um significado efetivo (Dreyfus, 2002). Como refere Vinner (1989), os alunos tendem a evitar a argumentação visual. Como a representação visual torna a compreensão dos conceitos da função derivada mais profunda e permite perceber a relação entre esses conceitos (Dreyfus, 2002), o NCTM (2008) recomenda a conexão entre as várias representações nas atividades de ensino e de aprendizagem por promoverem o raciocínio, a comunicação matemática e suportarem "o desenvolvimento dos conhecimentos" (p. 422).

\section{As representações no ensino de funções}

O pensamento matemático envolve diferentes processos, com destaque para a visualização por se tratar de "um processo através do qual as representações mentais ganham sentido" (Dreyfus, 2002, p. 31). Para Duval (2012), compreender um conceito matemático implica sermos capazes de diferenciar o objeto matemático da representação que o torna acessível: "os objetos matemáticos (...) não são objetos diretamente percetíveis ou observáveis com a ajuda de instrumentos” (p. 106). A única forma de lhes ter acesso e lidar com eles é a utilização de símbolos e representações. O termo representação significa, segundo Goldin (2002), "uma configuração que pode representar qualquer coisa de 
DOI: http://dx.doi.org/10.20396/zet.v25i2.8649274

determinada maneira" (p. 208), como por exemplo na forma de imagens e de objetos concretos (Gagatsis \& Elia, 2004).

Vários autores diferenciam as representações entre as externas e as internas (por exemplo, Dreyfus, 2002). As representações externas são personalizações de ideias ou conceitos - como são exemplo os mapas, as tabelas, os gráficos, os diagramas, os modelos e sistemas de símbolos formais -, através da "escrita ou da oralidade, geralmente com o objetivo de tornar a comunicação sobre o conceito mais fácil" (Dreyfus, 2002, p. 31). Friedlander e Tabach (2001) distinguem quatro modos diferentes de representação externa, que consideram serem essenciais no ensino da matemática e, mais especificamente, no ensino de tópicos algébricos: (i) verbal; (ii) numérica; (iii) gráfica; e (iv) algébrica.

As representações internas são as construções cognitivas que se formam na mente de um individuo (Goldin, 2002), designadas comummente por imagens mentais, que correspondem a "esquemas internos ou quadros de referência que uma pessoa usa para interagir com o mundo exterior. É o que ocorre na mente quando se pensa numa determinada parte do mundo externo e pode variar de pessoa para pessoa" (Dreyfus, 2002, p. 31). Para Almeida e Viseu (2002), este tipo de representações não são diretamente observadas e, por vezes, são encaradas como modelos mentais ou cognitivos referindo-se a esquemas, conceitos, concepções ou objetos mentais.

Para Duval (2012), as representações podem ser mentais, internas ou computacionais e semióticas. Para este autor, as representações mentais consistem num conjunto de imagens e conceções que um indivíduo pode ter sobre um objeto, sobre uma situação ou sobre aquilo que está associado ao objeto ou à situação. Tais representações estão associadas à interiorização das representações externas. As representações internas ou computacionais são aquelas que privilegiam o tratamento de uma informação, que por sua vez se caracteriza pela execução automática de uma determinada tarefa, a fim de produzir uma resposta adaptada à situação. Estas representações tratam, assim, da codificação de uma informação. As representações semióticas são produções constituídas pela aplicação de símbolos pertencentes a um sistema de representações que tem inconvenientes próprios de significação e de funcionamento. Uma figura geométrica, um enunciado em língua natural, uma fórmula algébrica, um gráfico são representações semióticas que exibem sistemas semióticos diferentes. Tais representações são externas e conscientes ao indivíduo e realizam a função de tratamento de forma intencional.

O termo registo de representação semiótica é usado por Duval para indicar diferentes tipos de representação como, por exemplo, a escrita em língua natural, a escrita algébrica, as tabelas, os gráficos cartesianos e as figuras. Segundo Duval (2012), os registos de representação semiótica são caracterizados por três atividades cognitivas: a primeira é a formação de uma representação identificável; a segunda é o tratamento, que é uma transformação que se efetua no interior de um mesmo registo; a terceira é a conversão, que é a transformação da representação de um objeto matemático em outra representação desse mesmo objeto. 
DOI: http://dx.doi.org/10.20396/zet.v25i2.8649274

Para além dessas atividades cognitivas, Duval (2012) distingue duas outras atividades distintas, a codificação e a interpretação, que não devem ser confundidas com a conversão. A interpretação "requer uma mudança de quadro teórico ou uma mudança de contexto. Esta mudança não implica mudança de registo" (Duval, 2012, p. 273). A codificação "é a 'transcrição' de uma representação em outro sistema semiótico diferente daquele em que é dado inicialmente" (Duval, 2012, p. 273). Esta transcrição, ao contrário da conversão, é efetuada aplicando regras de correspondência ou utilizando listas de substituições inicialmente estabelecidas que "são efetuadas diretamente sobre os significantes que compõem a representação, sem considerar a organização da representação, nem o que ela representa" (Duval, 2012, p. 273).

As múltiplas representações poderão ajudar na compreensão dos conceitos, porque as "conexões entre as múltiplas representações aumentam a redundância e podem, assim, reduzir as ambiguidades que podem aparecer numa representação particular" (Goldenberg, 1988, p. 7). Friedlander e Tabach (2001) acreditam que o trabalho com várias representações permite eliminar as limitações de cada uma delas, tornando "o processo de aprendizagem da Álgebra mais significativo e efetivo" (p. 173). Para podermos manipular com sucesso a informação que dispomos para a resolução de uma dada situação matemática, como por exemplo um problema, torna-se necessário que as várias representações estejam corretas e fortemente ligadas de modo a selecionar aquela que for mais eficiente para o próximo passo que queremos dar. $\mathrm{O}$ ensino e a aprendizagem deste processo de conexão entre as diferentes representações são difíceis por exigir capacidade de lidar com as diferentes formas de informação que elas veiculam. Os alunos revelam, geralmente, alguma falta de experiência e acabam por utilizar apenas uma das representações, o que pode dever-se a um ensino que valorize somente a representação simbólica. Ruthven (1993) tem reservas sobre "o tipo de ensino que se baseia fortemente na representação simbólica, porque essa abordagem tende a separar o argumento matemático do seu contexto original (...) e o enfoque passa a ser o símbolo como objeto em si mesmo" (p. 98). O uso de várias representações ajuda os alunos a fazer a transição de uma compreensão concreta e limitada de um tópico para outra mais abstrata e flexível (Dreyfus, 2002). Como forma de tirar partido das diferentes representações, Dreyfus (2002) defende que a complementaridade dos processos de abstração e de representação se pode desenvolver através de quatro fases: (i) utilizar uma só representação; (ii) utilizar mais que uma representação; (iii) estabelecer conexões entre representações; e (iv) integrar representações e ligações flexíveis entre elas. Esta forma de conceber a aprendizagem a partir das múltiplas representações tem em vista estabelecer uma concepção cada vez mais abstrata dos conceitos.

Existem vários estudos sobre as dificuldades sentidas pelos alunos na aprendizagem de conceitos relacionados com o Cálculo Diferencial (Azcárate et al., 1996; Dick, 1996; Ferrini-Mundy \& Lauren, 1994; Giraldo, Carvalho \& Tall, 2002). Conceitos como limite, continuidade e derivada são alguns exemplos que revelam maior complexidade na sua aprendizagem, não só devido à abstração inerente aos próprios conceitos, como também relativamente aos processos de representação envolvidos e que dificultam a sua compreensão 
DOI: http://dx.doi.org/10.20396/zet.v25i2.8649274

por parte dos alunos. O conceito de derivada pode ser definido de várias maneiras que devem ser compreendidas pelos alunos através das seguintes representações: gráfica, como o declive de uma reta tangente a uma curva num ponto; verbal, como taxa de variação instantânea; física, como a velocidade; simbólica, como o limite da razão incremental quando o incremento tende para zero. Tais representações fazem com que a compreensão da derivada de uma função dependa da forma como os alunos dominam os conceitos que lhes estão implícitos. Essa interdependência torna a compreensão da derivada mais complexa (Azcárate et al., 1996). Torna-se assim necessário o recurso a múltiplas representações para a promoção da compreensão do conceito de derivada de uma função pelo aluno, tendo sempre em consideração os conceitos que lhe estão subjacentes. Na aprendizagem do conceito de derivada, o destaque à exploração das regras de derivação tende a resultar num conhecimento superficial assente na manipulação algébrica sem o conhecimento significativo dos conceitos envolvidos (Dick, 1996). O papel da representação gráfica e da visualização é imprescindível numa experiência de ensino com ênfase numa abordagem gráfica para a compreensão dos conceitos de declive de uma reta, taxa de variação, limite, secantes, tangentes e derivada.

\section{Os recursos tecnológicos na aprendizagem da derivada de uma função}

A utilização de materiais tecnológicos (por exemplo, a calculadora gráfica) é recomendada pelos programas de matemática em vigor como forma de diversificar as representações dos conceitos matemáticos (Portugal, 2014). No que diz respeito ao cálculo infinitesimal, o NCTM (2008) recomenda um ensino "exploratório e baseado em experiências numéricas e geométricas que capitalizem o uso da calculadora (...). As atividades devem ter em vista fornecer aos alunos bases conceptuais firmes para o cálculo infinitesimal, em vez do desenvolvimento de técnicas manipulativas" (p. 215). Para Ruthven (1993), "o poder da calculadora gráfica reside na sua capacidade de facilitar a abordagem na sala de aula onde inicialmente as relações matemáticas são exploradas através da sua representação numérica ou gráfica de casos particulares" (p. 98).

A possibilidade de uma calculadora gráfica ajudar o cálculo intuitivo de limites permite verificar as conjecturas de aproximação gráfica e numérica dos conceitos de variação. Trata-se de algo relevante, na medida em que pode induzir o aluno na verificação de conjecturas e 'ver' a necessidade do cálculo do limite no conceito de derivada (García, 2000). Para este autor, a possibilidade do aluno poder calcular derivadas através da calculadora gráfica pode ser visto como algo negativo no sentido de desvalorizar a aprendizagem das regras de derivação. Todavia, como indica García (2000), existem vários estudos que mostram que os estudantes trabalham melhor quando conhecem o que a calculadora gráfica está a fazer, quando este não é um 'chapéu mágico', mas sim uma ferramenta que permite fazer, de maneira rápida e segura, as tarefas que eles sabem realizar por si mesmos.

Apesar de existirem estudos em que a utilização de calculadoras "em abordagens ativas e exploratórias da Matemática incentivam a curiosidade, o aumento de confiança e o gosto dos alunos por esta disciplina" (Ponte \& Canavarro, 1997, p. 121), existem outros 
DOI: http://dx.doi.org/10.20396/zet.v25i2.8649274

estudos que identificam alunos que "não encaram favoravelmente a utilização da calculadora" (idem). Atendendo que "as atitudes que os alunos desenvolvem relativamente à utilização da tecnologia do ensino está fortemente relacionada com o tipo de atividades que realizam" (Ponte \& Canavarro, 1997, p. 122), dever-se-á recorrer a tarefas de natureza aberta com análise crítica dos resultados.

\section{Metodologia}

Este estudo pretende averiguar o contributo das representações na aprendizagem da derivada de uma função de alunos portugueses do 11. ${ }^{\circ}$ ano de Matemática A. Nas estratégias de ensino, os tópicos de derivadas foram estudados a partir de tarefas que implicavam, na maior parte delas, a utilização da calculadora gráfica. Esta experiência decorreu durante oito aulas. Atendendo à natureza do objetivo delineado, adotámos uma abordagem qualitativa e interpretativa na procura de compreender a atividade dos alunos na resolução de tarefas em contexto de sala de aula (Bogdan \& Biklen, 1994). Com esta finalidade, os dados foram recolhidos através dos registos escritos que os alunos produziram na resolução das tarefas propostas com recurso à calculadora gráfica.

A turma onde se realizou esta experiência era do $11 .^{\circ}$ ano de Matemática A, do Curso de Ciências e Tecnologia, constituída por 21 alunos, dos quais 9 eram rapazes e 12 raparigas, com idades de 16 e 17 anos. A turma não tinha alunos com retenções no $11 .^{\circ}$ ano e a média das classificações finais de Matemática no $10 .^{\circ}$ ano de escolaridade foi de 11,8 valores, em que a nota mais alta foi de 17 valores e a mais baixa de 8 valores. Quatro alunos da turma repetiram o $10 .^{\circ}$ ano e três desses alunos tiveram negativa no $1 .^{\circ}$ e $2 .^{\circ}$ período do corrente ano letivo. As médias dos alunos nos $1 .^{\circ}, 2^{\circ}$ e $3 .^{\circ}$ períodos foram, de 0 a $20,11,2 ; 11,4$ e 12,7 valores, respetivamente. A média no terceiro período subiu sensivelmente devido à desistência de um aluno que nos períodos anteriores foi classificado de 7 valores. Todos os alunos da turma $(n=20)$ possuíam calculadora gráfica. De um modo geral, os alunos utilizavam a calculadora apenas como um auxiliar nas operações aritméticas simples e não revelavam a capacidade de iniciativa para a exploração das diversas potencialidades oferecidas pela calculadora quando confrontados com novas situações e novos conceitos.

A informação recolhida, que resulta da resolução de cinco tarefas, é analisada e apresentada segundo os seguintes tópicos que foram lecionados: (i) Variação e taxa média de variação de uma função num intervalo de IR; (ii) Taxa de variação; e (iii) Variação e extremos relativos de uma função. Em cada um destes tópicos adotam-se os modos de representação enunciados por Friedlander e Tabach (2001), à exceção da representação verbal, e ainda a representação tabelar (Brown \& Mehilos, 2010). O termo tradução utilizado por outros autores (Janvier, 1987; Vinner, 1989) é englobado no termo conversão definido por Duval (2012) para a análise dos dados. Usam-se os termos codificação, interpretação e tratamento segundo o referencial teórico de Duval. 
DOI: http://dx.doi.org/10.20396/zet.v25i2.8649274

\section{Apresentação dos resultados}

\section{Variação e taxa média de variação de uma função num intervalo de IR}

No desenvolvimento deste tópico foram realizadas tarefas pelos alunos e promovidas discussões orientadas com base nos conhecimentos prévios que os alunos têm sobre velocidade, em particular, velocidade média. Como referem Azcárate et al. (1996), não é eficaz iniciar a aprendizagem do conceito de derivada através do conceito de limite sem primeiro consolidar os conhecimentos ao nível dos conceitos e do cálculo dos requisitos prévios. O desenvolvimento do tópico resultou da resolução de duas tarefas (Tarefa 1 e Tarefa 2) com um grau de dificuldade reduzido.

\section{Tarefa 1}

Numa corrida bicicleta organizada na escola, o Pedro fez os tempos indicados na tabela:

\begin{tabular}{|c|c|c|c|c|c|c|}
\hline $\mathbf{t}(\mathbf{s})$ & 0 & 8,5 & 17,5 & 27,5 & 39,5 & 53 \\
\hline $\mathbf{d}(\mathbf{m})$ & 0 & 200 & 400 & 600 & 800 & 1000 \\
\hline
\end{tabular}

1. Qual é o total de metros da corrida?

2. Qual é a distância percorrida quando $t=8,5 s$ ?

3. Em que instante a distância assume maior valor

4. Qual é a variação da distância quando o tempo varia de 8,5 a 27,5 s?

5. Qual é a variação do tempo quando a distância varia entre 600 e 1000 ?

6. Qual foi a velocidade média do Pedro no total do percurso?

7. Qual é a velocidade média em cada um dos intervalos considerados?

8. Quando revelou o Pedro sinais de "cansaço"? Justifique a sua resposta.

9. Represente num plano cartesiano os pontos $(t, d)$ obtidos da tabela.

10. Da análise da velocidade média do Pedro nos intervalos de tempo considerados, registe a interpretação que retira da representação gráfica, numérica e da tabelar.

Com esta tarefa, os alunos trabalharam conceitos básicos de Cinemática, em particular o conceito de velocidade média, e chegaram ao conceito de taxa média de variação. Os alunos codificaram corretamente os dados fornecidos pela representação tabelar. Reponderam às três primeiras questões diretamente dos dados da tabela usando a representação numérica, uma opção previsível já que as questões pediam valores numéricos da tabela, como exemplifica a resposta do aluno A16:

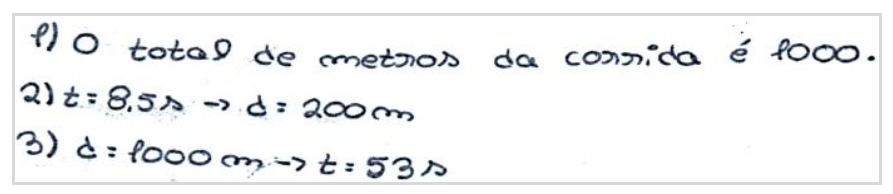

Figura 1. Resposta dada pelo aluno A16 às três primeiras questões da Tarefa 1.

Nas questões seguintes (da 4 à 7), os alunos codificaram os dados da representação tabelar e utilizaram, corretamente, a representação numérica para obter a variação da distância e do tempo e da velocidade média, como revela a resolução do aluno A10. 
DOI: http://dx.doi.org/10.20396/zet.v25i2.8649274

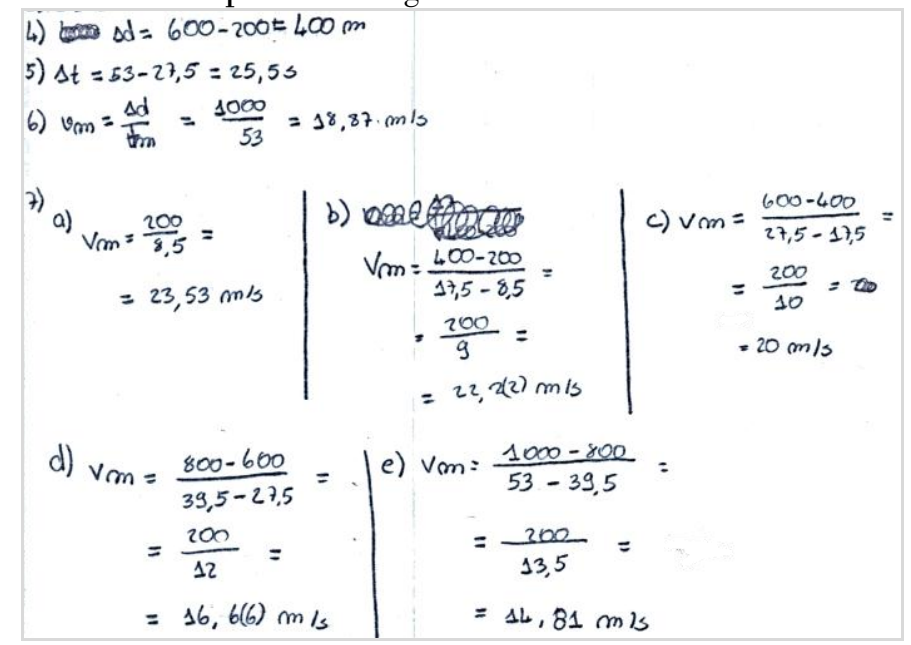

Figura 2. Resposta dada pelo aluno A10 às questões 4 a 7 da Tarefa 1.

As questões da tarefa influenciaram, novamente, a representação utilizada pelos alunos (Friedlander \& Tabach, 2001).

Para justificarem em que momento o Pedro apresenta cansaço, os alunos usaram a representação numérica. O objetivo desta questão foi confrontar os alunos com uma situação em que tinham de entender o significado dos dados que obtiveram na determinação da velocidade média nos intervalos considerados. Os alunos não apresentaram dificuldades em responder a esta questão. Da análise das respostas dadas, novamente se verifica o recurso à representação numérica como base na explicitação do seu raciocínio. Nesta questão, os alunos foram influenciados pelos resultados já obtidos nas questões anteriores, já que a questão não indicia a representação a utilizar, como ilustra a resposta do aluno A17.

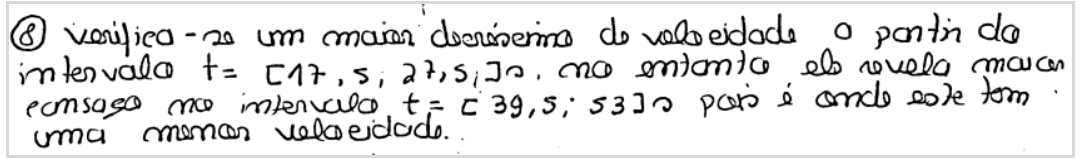

Figura 3. Resposta do aluno A17 à questão 8 da Tarefa 1.

Nas respostas anteriores, os alunos, na sua maioria, não tiveram dificuldades devido, em parte, ao processo de tratamento de representações semióticas, que as tarefas implicavam, não ser de grande dificuldade. A maior parte dos alunos utilizou a representação numérica devido ao tipo de conhecimento matemático que as questões evocam.

$\mathrm{Na}$ questão seguinte, pretendia-se que os alunos representassem no plano cartesiano os pontos obtidos a partir da representação tabelar. Seis alunos não responderam e uma grande parte evidenciou dificuldades no processo de conversão da representação tabelar para a representação gráfica, como exemplifica a dificuldade do aluno A18 em definir a escala do gráfico em função dos dados fornecidos. 
DOI: http://dx.doi.org/10.20396/zet.v25i2.8649274

9)

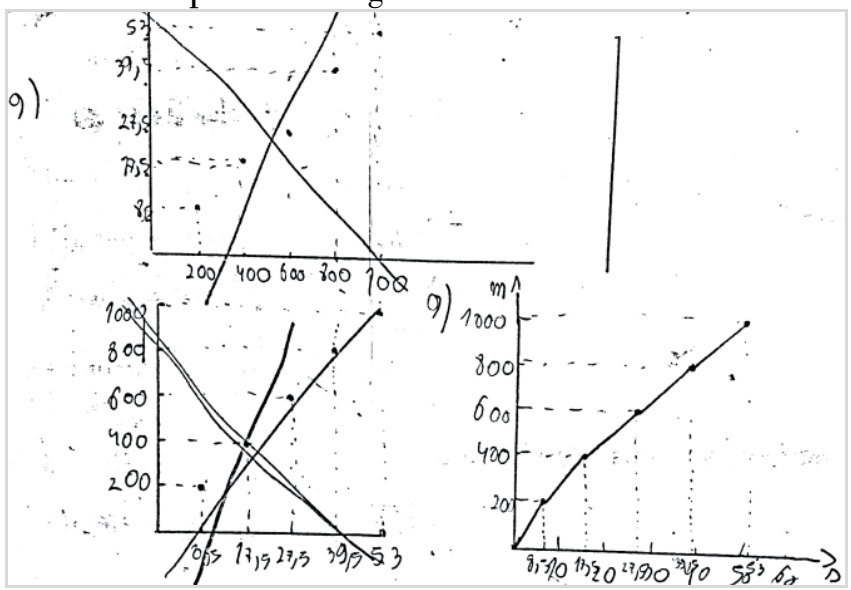

Figura 4. Resposta do aluno A18 à questão 9 da Tarefa 1.

Na representação gráfica da situação contemplada na Tarefa 1, os alunos tendem a unir os pontos por segmentos de reta sem que lhes seja dito que a velocidade média atingida em cada um dos intervalos considerados é constante, como ilustra a representação gráfica efetuada pelo A18. A tendência dos alunos unirem os pontos por segmentos de reta parece indiciar que eles não distinguem claramente a taxa de variação média da taxa de variação instantânea.

Por fim, a última questão solicitava a análise das várias representações presentes na resolução da tarefa. Da análise das produções dos alunos verificou-se que dez alunos usaram a representação gráfica, como suporte para a sua argumentação, e dez não responderam. Estes alunos não conseguiram representar graficamente a informação fornecida pela representação tabelar. A Figura 5 apresenta um exemplo de uma resposta onde explicitamente o aluno refere a representação gráfica como fonte para a sua argumentação sobre a variação da velocidade média do Pedro em cada um dos intervalos considerados.

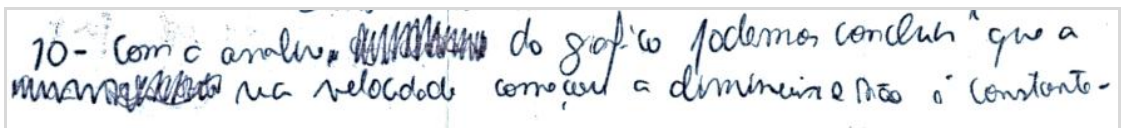

Figura 5. Resposta do aluno A22 à questão 10 da Tarefa 1.

Após o término da tarefa proposta foi pedido aos alunos a resolução de outra tarefa (Tarefa 2), com a finalidade de analisar a relação existente entre taxa média de variação e monotonia da função num dado intervalo do seu domínio e abordar a interpretação geométrica da taxa média de variação de uma função num dado intervalo do seu domínio. Adotou-se, novamente, uma abordagem na senda de Dreyfus (2002), mas começando intuitivamente pela representação gráfica até a uma formalização algébrica do conceito. Os dados foram fornecidos por uma representação gráfica e foi solicitado aos alunos que a interpretassem e codificassem. 
DOI: http://dx.doi.org/10.20396/zet.v25i2.8649274

\section{Tarefa 2}

Observe o gráfico e indique:

1. Um intervalo onde a taxa média de variação seja positiva e monótona crescente.

2. Um intervalo onde a taxa média de variação seja positiva e a função não seja monótona.

3. Um intervalo onde a taxa média de variação seja negativa.

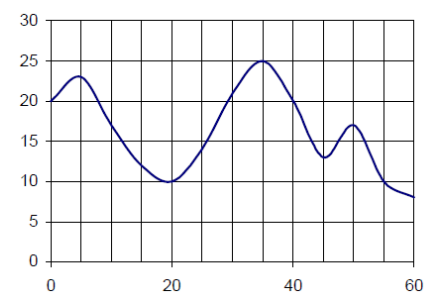

4. Um intervalo onde a taxa média de variação seja nula

5. Um intervalo onde a taxa média de variação seja negativa e a função não seja monótona.

6. A equação de reta definida pelos pontos de abcissa 20 e 40. Encontra alguma relação entre a taxa média de variação e o declive $(\mathrm{m})$ da reta?

Os alunos poderiam ter respondido recorrendo exclusivamente aos dados fornecidos pelo gráfico, apresentando apenas o intervalo, ou os intervalos e calcular a sua taxa média de variação para justificar a resposta. A maioria dos alunos apresentou o intervalo e calculou a taxa média de variação (Figura 6).

$$
\begin{aligned}
& { }_{\text {(1) }} v_{[20.35]}=\frac{f(35)-f(20)}{35-20}=\frac{25-10}{35-20}=\frac{15}{15}=1 \\
& D_{f \cdot m \cdot v}[20,40]=\frac{f(40)-1(20)}{40-20}=\frac{20-10}{40-20}=\frac{10}{20}=\frac{1}{2} \\
& \text { (3) } f_{t \cdot m v}[5,20]=\frac{f(20)-f(s)}{20-5}=\frac{10-22,5}{15}=-0,8(3) \\
& \text { (4) } t_{\text {m. }:[0,8]}=\frac{f(8)-t(0)}{8-10}=\frac{20-20}{2}=\frac{0}{2}=0 \\
& \text { (5): }{ }_{\left.t \cdot m \cdot v_{[35,55}\right]}=\frac{f(s s)-f(35)}{s 5-35}=\frac{10-25}{20}=\frac{-15}{20}=\frac{-3}{4}
\end{aligned}
$$

Figura 6. Resposta do aluno A17 às questões 1 a 5 da Tarefa 2.

Apenas dois alunos apresentaram só os intervalos

$$
\begin{aligned}
& \text { 3) 15 } \\
& \text { 4) } 330 ; 40[ \\
& \text { (5) stro:sisp] } 35: 55[
\end{aligned}
$$

Figura 7). Um desses alunos recorreu apenas à codificação da representação gráfica nas duas primeiras questões e noutras à gráfica e numérica, como se pode verificar na (1).

Pelu obser araqué do gaófico, o taxa média de voniagú

$e^{\prime}$ positiras monótona ereneente em $[5,10]$.

(2). Pela obsernoepá do sráfico, $[40,50]$

(3) $l \cdot m \cdot v \cdot[5,20]=\frac{f(20)-f(5)}{20 \cdot 5}=\frac{10-22,5}{20 \cdot 5}=\frac{-12,5}{15}=-0,83(3)$

Figura 8.

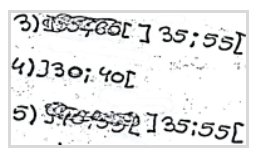

Figura 7. Resposta do aluno A16 às questões 3 a 5 da Tarefa 2. 


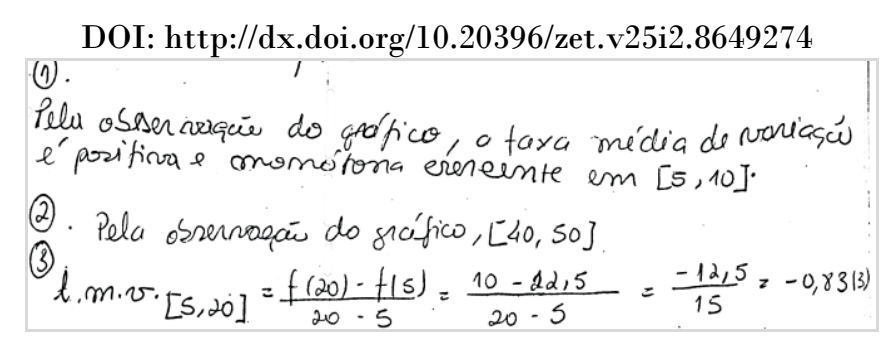

Figura 8. Resposta do aluno A15 às questões 1 a 3 da Tarefa 2.

$\mathrm{Na}$ resposta do aluno A15, é reveladora a adequação que fez entre as várias representações. Como a taxa média de variação não é suficiente para justificar a não monotonia do intervalo, o aluno responde apenas com o intervalo. A maioria dos alunos justificou o intervalo dado como resposta, mesmo não sendo pedido. Este comportamento pode estar relacionado com o valor que os alunos atribuem à interpretação exclusiva da representação gráfica.

Para além das formas de representação já referidas anteriormente, os alunos fizeram uso também da representação algébrica. Por exemplo, a utilização da representação algébrica na resolução da última questão revela que os alunos têm a capacidade de estabelecer relações entre os conceitos apreendidos. Neste caso, a totalidade dos alunos respondeu corretamente a essa questão utilizando a representação algébrica, como exemplifica a resposta dada pelo aluno A16:

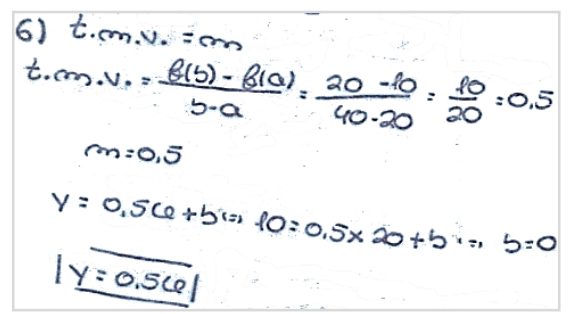

Figura 9. Resposta do aluno A16 à questão 6 da Tarefa 2.

Apenas um aluno utilizou corretamente a notação do cálculo da taxa média de variação. Como se pode verificar na resposta da Figura 9, o aluno não especificou o intervalo para o qual está a calcular a taxa média de variação. Esta falta de rigor poderá estar relacionada com a recente utilização do conceito ou com a relação que fez mentalmente com a forma que normalmente estão habituados para calcular o declive de uma reta.

\section{Taxa de variação}

A noção de taxa média de variação num intervalo serviu de requisito para a introdução da taxa de variação local de uma dada função através da resolução da Tarefa 3. A transição do conceito de taxa média de variação de uma função num dado intervalo do seu domínio para a noção de derivada num valor do domínio da função decorre numa fase em que o aluno ainda não tem bem presente a perceção dinâmica do comportamento de uma função na vizinhança de um dado valor no seu domínio.

\section{Tarefa 3}

Uma bola desce um plano inclinado e registou-se a distância percorrida pela bola no decorrer do tempo. A distância (d), em centímetros, percorrida pela bola em função 
DOI: http://dx.doi.org/10.20396/zet.v25i2.8649274

do tempo $(t)$, em segundos, é dada por $d(t)=10 t^{2}$

1. Represente graficamente a função $d$ na situação descrita.

2. Calcule a taxa média de variação no intervalo $[1,2]$.

3. Preencha as seguintes tabelas:

\begin{tabular}{|c|c|}
\hline Intervalo & t.m.v. \\
\hline$[1 ; 1,5]$ & \\
\hline$[1 ; 1,1]$ & \\
\hline$[1 ; 1,01]$ & \\
\hline$[1 ; 1,001]$ & \\
\hline
\end{tabular}

Tabela 1

\begin{tabular}{|c|c|}
\hline Intervalo & t.m.v. \\
\hline$[0,5 ; 1]$ & \\
\hline$[0,9 ; 1]$ & \\
\hline$[0,99 ; 1]$ & \\
\hline$[0,999 ; 1]$ & \\
\hline
\end{tabular}

Tabela 2

4. Seja $h>0$ um acréscimo no intervalo $[1 ; 1+\mathrm{h}]$, à semelhança do efetuado na tabela

1, com $\mathrm{h}$ a tender para zero. Calcule a taxa média de variação da função no intervalo $[1 ; 1+\mathrm{h}]$. Conjeture para que valor tende a $t . m . v_{*}[1,1+h]$ quando $\mathrm{h}$ tende para zero.

5. Faça uma estimativa da velocidade da bola no instante $1 s$. Justifique.

6. Indique a equação de reta definida pelos pontos $(1, \mathrm{~d}(1))$ e $(2, \mathrm{~d}(2))$ e represente a reta em conjunto com a representação do gráfico da função $d$.

7. Preencha a seguinte tabela e represente as equações das retas que passam nos pontos que têm como abcissas os extremos dos intervalos da Tabela 1.

\begin{tabular}{|c|c|}
\hline Intervalo & Equação de reta \\
\hline$[1 ; 1,5]$ & \\
\hline$[1 ; 1,1]$ & \\
\hline$[1 ; 1,01]$ & \\
\hline$[1 ; 1,001]$ & \\
\hline$\ldots$ & \\
\hline$[1 ; 1+\mathrm{h}]$ & $\ldots$ \\
\hline
\end{tabular}

8. Conjeture sobre a reta que se obtém quando a amplitude do intervalo tende para zero.

Com esta tarefa, pretendia-se que os alunos compreendessem que apenas a taxa média de variação não é suficiente para saber o comportamento de uma função num ponto e, assim, despertar a necessidade de um novo 'instrumento' matemático. A tarefa propunha uma série de questões que, de forma gradual, promoviam um raciocínio do particular para o geral, através do trabalho com várias representações dos conceitos, algébrica e gráfica, num processo de tradução/conversão entre representações (Duval, 2012). Os conceitos foram apresentados inicialmente através da representação algébrica e depois foi introduzida a representação gráfica em paralelo, para, por fim, estabelecer relações entre elas (Dreyfus, 2002).

$\mathrm{Na}$ representação gráfica da função dada através de uma representação algébrica, dos Zetetiké, Campinas, SP, v.25, n.2, maio./ago.2017, p.265-288. 
DOI: http://dx.doi.org/10.20396/zet.v25i2.8649274

dezanove alunos que responderam à tarefa, nove recorreram à representação tabelar e à gráfica. A representação tabelar/numérica foi utilizada para cálculos auxiliares de alguns pontos, como mostra a resolução do aluno A10.
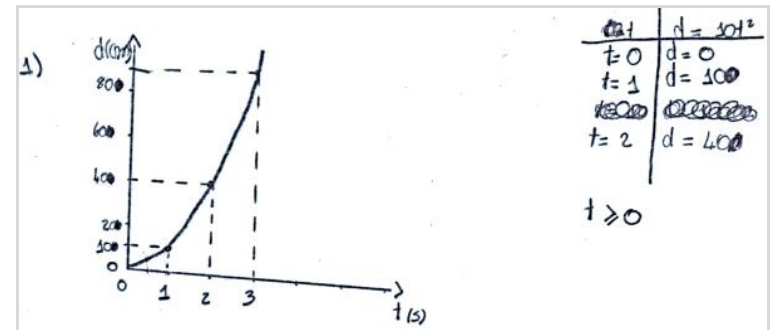

Figura 10. Resposta do aluno A10 à questão 1 da Tarefa 3.

Os alunos não apresentaram dificuldades em esboçar o gráfico e tiveram em conta o contexto do problema. A realização sem dificuldades da conversão da representação algébrica para a representação gráfica traduz o fenómeno de congruência entre estas representações (Duval, 2012). As representações gráficas produzidas pelos restantes dez alunos, sem os respetivos cálculos auxiliares, resultaram da utilização da calculadora gráfica.

$\mathrm{Na}$ mudança da representação algébrica para a representação gráfica, o facto de os alunos utilizarem sobretudo processos numéricos para determinarem as coordenadas de pontos, mostra a importância destes processos na compreensão inicial de um problema tal como é defendido por Friedlander e Tabach (2001). Neste caso, os alunos começaram por atribuir valores a $x$ na expressão algébrica, determinaram os respetivos valores de $y$, obtiveram as coordenadas de pontos, e com base nesses pontos construíram parte da parábola correspondente ao gráfico da função. Este conjunto de procedimentos são corroborados pelos resultados observados por Leinhardt et al. (1990), que indicam que a construção do gráfico a partir da expressão algébrica resume-se a uma série de passos diretos, que normalmente passam por identificar pares ordenados, representá-los no referencial cartesiano e traçar uma curva que passe pelos pontos assinalados.

$\mathrm{Na}$ terceira questão, a turma foi questionada sobre a estimativa do valor da t.m.v. se continuassem a diminuir a amplitude do intervalo. Os alunos, na sua maioria, responderam corretamente a esta questão, utilizando exclusivamente a representação numérica. A maioria dos alunos não apresentou os cálculos da t.m.v. para cada um dos intervalos como ilustra a resposta do aluno A13.

\begin{tabular}{|l|c|}
\hline Intervab & t.m.v \\
\hline$[1 ; 1,5]$ & 25 \\
\hline$[1 ; 1,1]$ & 21 \\
\hline$[1 ; 1,01]$ & 20,1 \\
\hline$[1 ; 1,001]$ & 20,01 \\
\hline
\end{tabular}$\quad$\begin{tabular}{|c|c|}
\hline Intervals & $t \cdot m \cdot v$ \\
\hline$[0 ; 5 ; 1]$ & 15 \\
\hline$[0,9 ; 1]$ & 19 \\
\hline$[0,99 ; 1]$ & 19,9 \\
\hline$[0,999 ; 1]$ & 19,99 \\
\hline
\end{tabular}

Figura 11. Resposta do aluno A13 à questão 3 da Tarefa 3.

Os restantes alunos apresentaram os cálculos, como é exemplo a resposta do aluno 
DOI: http://dx.doi.org/10.20396/zet.v25i2.8649274

A5, apesar da falta de rigor, em particular, nas casas decimais.

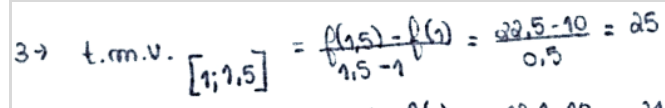

$$
\begin{aligned}
& \text { t.m. v. }[1 ; 1,1]=\frac{f(1,1)-f(1)}{1,1-1}=\frac{12,1-10}{1,1-1}=21 \\
& \text { t.m.v. }[1 ; 1,1]=\frac{f(1,01)-f(1)}{1,01-1}=\frac{10,201-10}{0,01}=20,1 \\
& \text { t. .ron.v }[1,0 ; 3,001]=\frac{f(1,001) f(1)}{1,001-1}=\frac{10,220-10}{0,001}=20 \\
& \text { t.m. v. }[0,5,1]=\frac{f(1)-f(0,5)}{1-0,5}=\frac{10-2,5}{1-0,5}=15 \\
& \text { t.on.v. }[0,3 ; 1]=\frac{f(1)-f(0,9)}{1-0,9}=\frac{10-8,1}{1-0,9}=19 \\
& \text { t.m. } v_{[0,99 ; 1]}=\frac{f(1)-f(0,99)}{1-0,99}=\frac{10-9,801}{1-0,99}=19,9 \\
& \operatorname{tcon} v^{v}[0,999 ; 1]=\frac{f(1)-f(0,999)}{1-0,999}=\frac{10-9,9800}{1-0,999}=20
\end{aligned}
$$

Figura 12. Resposta do aluno A5 à questão 3 da Tarefa 3.

A quarta questão da Tarefa 3 serviu para estabelecer uma ligação entre os valores obtidos na questão anterior e o cálculo da taxa média de variação no intervalo $[1 ; 1+\mathrm{h}]$. Os alunos utilizaram a representação algébrica apesar de evidenciarem falta de rigor na manipulação algébrica. Alguns alunos não manifestaram dificuldades em responder à questão, como exemplifica a resposta do aluno A5, embora não apresente em todas as expressões a referência ao limite:

$$
\begin{aligned}
& \text { 4. } \rightarrow f(1+h)=10 \times(1+h)^{2}=10 \times\left(1^{2}+2 h+h^{2}\right)=10+20 h+20 h^{2} \\
& \text { t.en .v. }[1 ; 1+h]=\frac{f(1+h)-f(1)}{1+h-1}=\frac{30+20 h+10 h^{2}-10}{1+h-1}=\frac{h(20+10 h)}{h}=20+10 h \\
& \lim _{h \rightarrow 0} \quad \frac{f(1+h)-f(1)}{1+h-1}=\frac{6+20 h+20 h^{2}-10}{h+h-h}=\frac{\not(20+10 h)}{x}=20 \text {. }
\end{aligned}
$$

Figura 13. Resposta do aluno A5 à questão 4 da Tarefa 3.

Já outros alunos revelam falta de rigor e dificuldade na manipulação de expressões algébricas, como ilustra a resposta do aluno A12:

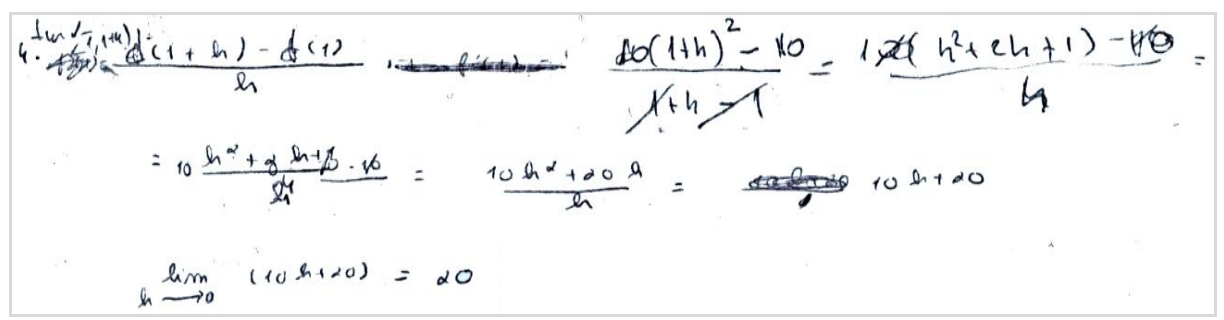

Figura 14. Resposta do aluno A12 à questão 4 da Tarefa 3.

Após a determinação da expressão algébrica da t.m. $v_{\cdot[1,1+h]}$, os alunos foram questionados se existe e qual a relação entre o valor 20, obtido na questão anterior, e o valor da t.m. $v_{r}[1,1+h]$. Com esta questão pretendia-se que os alunos estabelecessem a conexão entre 
DOI: http://dx.doi.org/10.20396/zet.v25i2.8649274

a representação tabelar e a representação algébrica, o que revelou ser complexa para os alunos.

A quinta questão da Tarefa 3 tinha como objetivo confrontar os alunos, com os conhecimentos que possuíam, com a obtenção do valor para a velocidade no instante 1s. Pelas produções dos alunos, verifica-se que não conseguiram chegar a nenhuma conclusão correta e que utilizaram apenas a representação algébrica, como ilustram as respostas dadas pelos alunos A 9 e A 17.

$$
\begin{aligned}
& \text { 5) } d(1)=10 \times 1^{2} \Leftrightarrow d(1)=10 \mathrm{~cm} \quad \text { (5) Quando } t=1 \mathrm{~s}, d=100 \mathrm{~m} \\
& \left.v=\frac{\Delta d}{\Delta t} \Leftrightarrow=\frac{10-0}{1-0} \Leftrightarrow v=10 \mathrm{~m}\right) / \mathrm{s}
\end{aligned}
$$

Figura 15. Respostas erradas dos alunos A9 e A17 à questão 5 da Tarefa 3.

$\mathrm{Na}$ apreensão do novo conceito, procurou-se estabelecer uma ligação com as questões anteriores, esperando-se que os alunos entendessem que a velocidade num determinado instante teria de ser calculada através da taxa média de variação.

A sexta questão pedia a equação de reta definida por dois pontos e a representação da reta em conjunto com a representação do gráfico da função $d$. Os alunos conseguiram obter a equação da reta pedida utilizando os novos conhecimentos, neste caso particular a taxa média de variação, e relacioná-la com o declive, como mostra a seguinte resposta:

$$
\begin{gathered}
\text { 6.t.m.v }[1, x]=m=30 \\
\log 0 y=m x+b 17 \\
y y=30 x-20
\end{gathered}
$$

Figura 16. Resposta do aluno A12 à questão 6 da Tarefa 3.

Relativamente à segunda parte desta questão, que pedia uma conversão da representação algébrica na gráfica, os alunos tiveram muitas dificuldades. Apenas dois alunos responderam à questão, sem indicarem o ponto de interseção $(2, d(2))$ entre a reta e o gráfico da função, como mostra a seguinte resposta de um desses alunos.

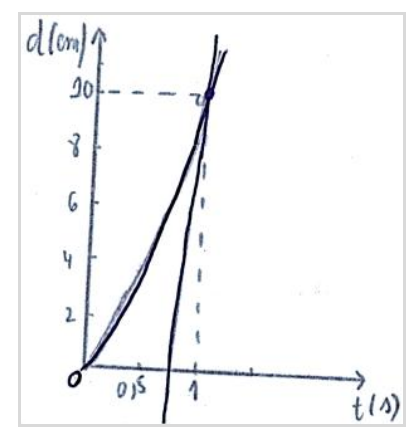

Figura 10. Resposta do aluno A2 à questão 6 da Tarefa 3.

A resolução desta questão no quadro foi aproveitada para representar a reta secante na calculadora gráfica e projetá-la no quadro que serviria para realizar a questão seguinte. 
DOI: http://dx.doi.org/10.20396/zet.v25i2.8649274

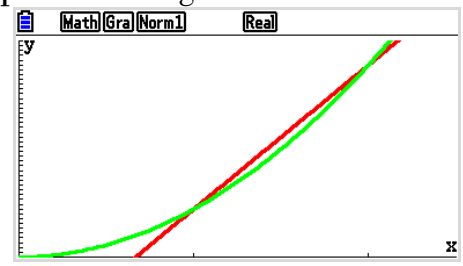

Figura 18. Representação gráfica da questão $6([0 ; 0.25]$ x [0; 45]).

Na sétima questão, os alunos não tiveram dificuldade em obter as equações de reta dos intervalos considerados. Em conjunto com os alunos, foi definido a interpretação geométrica da taxa de variação de uma função quando $x=x_{0}$. Tendo em consideração os valores obtidos na Tabela 1, apresentada na tarefa, foram determinadas as equações de reta e as suas representações gráficas nos pontos que têm como abcissas os extremos dos intervalos considerados:

\begin{tabular}{|c|c|}
\hline Intervalo & Equação de reta \\
\hline$[1 ; 1,5]$ & $y=25 x-15$ \\
\hline$[1 ; 1,1]$ & $y=21 x-11$ \\
\hline$[1 ; 1,01]$ & $y=20,1 x-10,1$ \\
\hline$[1 ; 1,001]$ & $y=20,01 x-10,01$ \\
\hline$\ldots$ & $\ldots$ \\
\hline$[1 ; 1+\mathrm{h}]$ & $y=(10 h+20) x+(-10-10 h)$ \\
\hline
\end{tabular}

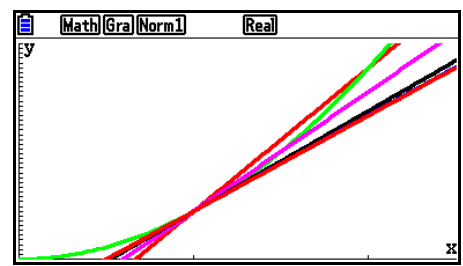

Figura 19. Representação gráfica da reta tangente ao gráfico da função definida por $d(t)=10 t^{2}$ no ponto de abcissa 1 .

Variação e extremos relativos de uma função

A estratégia adotada para que os alunos relacionassem o sinal da função derivada com a monotonia da função e com a possível existência de extremos relativos teve como suporte a representação gráfica da função e da respetiva função derivada em simultâneo. Foi apresentado aos alunos uma animação que evidenciava a construção do gráfico da função derivada a partir do gráfico da função dada (Figura 20)

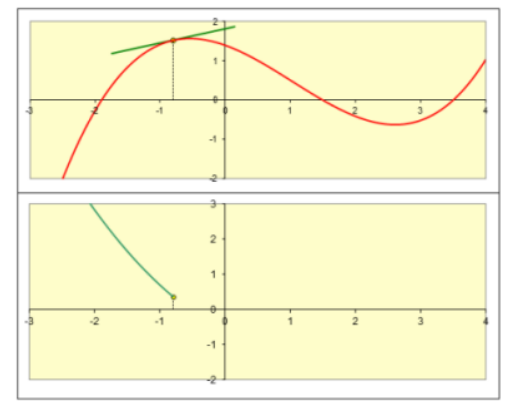

Figura 20. Construção da função derivada a partir das tangentes ao gráfico da função. 
DOI: http://dx.doi.org/10.20396/zet.v25i2.8649274

Após a análise da animação, os alunos resolveram a primeira questão da seguinte tarefa:

\section{Tarefa 4}

Admita que a expressão que define a função representada graficamente é:

$T(t)=\frac{t^{3}}{3}-2 t^{2}+3 t+3 ; t \in\left[0, \frac{9}{2}\right]$

1. Determine $\mathrm{T}^{\prime}(\mathrm{t})$.

2. Estude analiticamente o sinal da função $T^{\prime}$.

3. Sabendo que às 3 horas a temperatura atingiu um mínimo no intervalo dado, indique a que hora a temperatura foi máxima nesse intervalo. Justifique o seu raciocínio.

Dois alunos utilizaram a definição de derivada de uma função para obter a função derivada, os restantes alunos utilizaram as regras de derivação. Todos responderam através do tratamento algébrico.

Na segunda questão, os alunos, na sua maioria, conseguiram fazer o estudo do sinal da função derivada da função T no domínio dado e utilizaram mais do que uma representação, como ilustra a resposta do aluno A11:

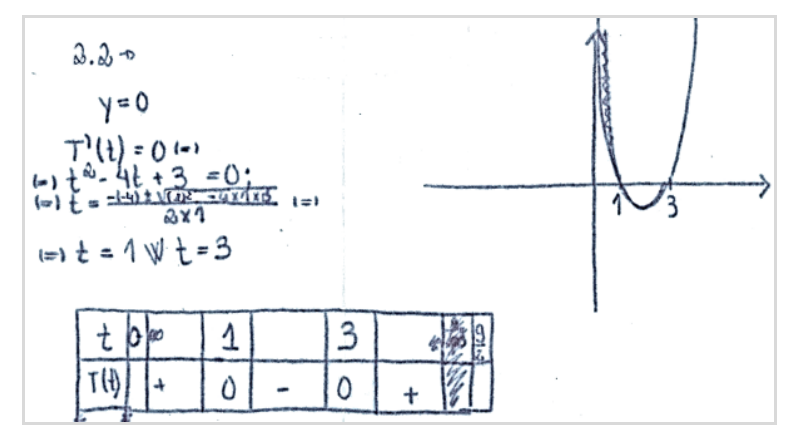

Figura 21. Resposta do aluno A11 à questão 2 da Tarefa 4.

O aluno recorre à representação gráfica da função derivada, no domínio considerado, como auxiliar para identificar os intervalos onde esta função tem valores positivos e negativos. Utilizou a representação algébrica para derivar a função através das regras de derivação e para obter os zeros da função derivada. Por fim, construiu a tabela que poderia usar para estudar os intervalos de monotonia e os extremos da função, o que o aluno não fez.

A terceira questão serviu para estabelecer a relação existente entre a monotonia de uma função e o sinal da sua derivada e entre os extremos de uma função, caso existam, e os zeros da sua derivada. Poucos alunos responderam a esta questão e os que responderam e a justificaram utilizaram a representação gráfica $(n=7)$ ou numérica $(n=2)$. Como exemplo das respostas dos dois alunos que recorreram à representação numérica é a resposta dada pelo aluno A5, que indicia ter concluído que foi na primeira hora que a temperatura foi máxima através da interpretação do gráfico, sem recorrer à derivada da função. 
DOI: http://dx.doi.org/10.20396/zet.v25i2.8649274

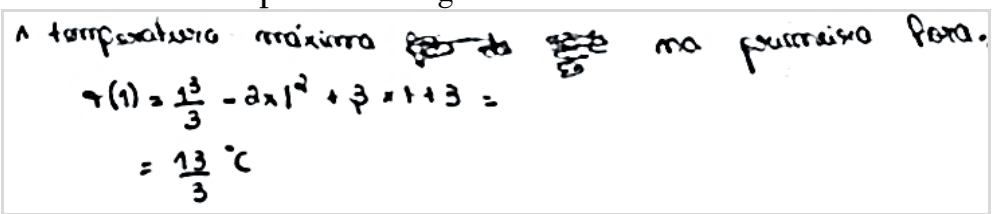

Figura 22. Resposta do aluno A5 à questão 3 da Tarefa 4.

Outros alunos, como são o caso dos alunos A8 e A7, recorreram à sobreposição do gráfico da função e da função derivada para assinalar o ponto onde a temperatura é máxima.

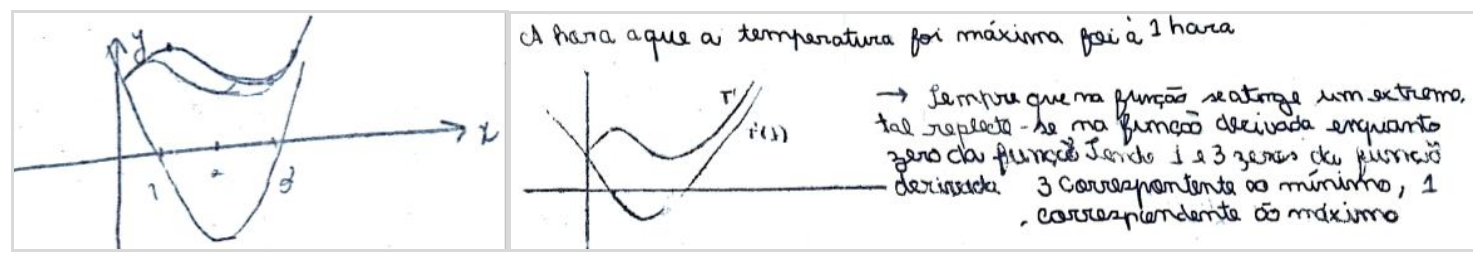

Figura 23. Respostas dos alunos A8 e A7 à questão 3 da Tarefa 4.

Este tipo de relações entre as representações gráficas de funções diferentes, relacionando as suas características, faz com que a visualização seja essencial para o desenvolvimento do pensamento algébrico levando os alunos a aproximarem o conceito imagem do conceito definição de função (Vinner, 1983).

Os dez alunos que não responderam/justificaram revelam que tiveram dificuldades em estabelecer conexões entre os conceitos através da representação gráfica, neste caso particular entre a função e a sua função derivada, como também foi observado por Ferrini-Mundy e Lauten (1994).

Na resolução de outras tarefas, os alunos puderam analisar casos relacionados com a existência de extremos de uma função. Os alunos foram assim confrontados com exemplos que ajudam a identificar a relação entre o sinal da derivada e a existência de extremos.

\section{Tarefa 5}

Estuda a existência de extremos das seguintes funções. Justifique.

a) $f(x)=-x^{3}+12 x+5$

b) $f(x)=|x+1|$

$\mathrm{Na}$ primeira questão, os alunos utilizaram mais do que uma representação, como ilustra a resolução do aluno $\mathrm{A} 8$, com recurso à calculadora gráfica para obter as representações gráficas: 
DOI: http://dx.doi.org/10.20396/zet.v25i2.8649274

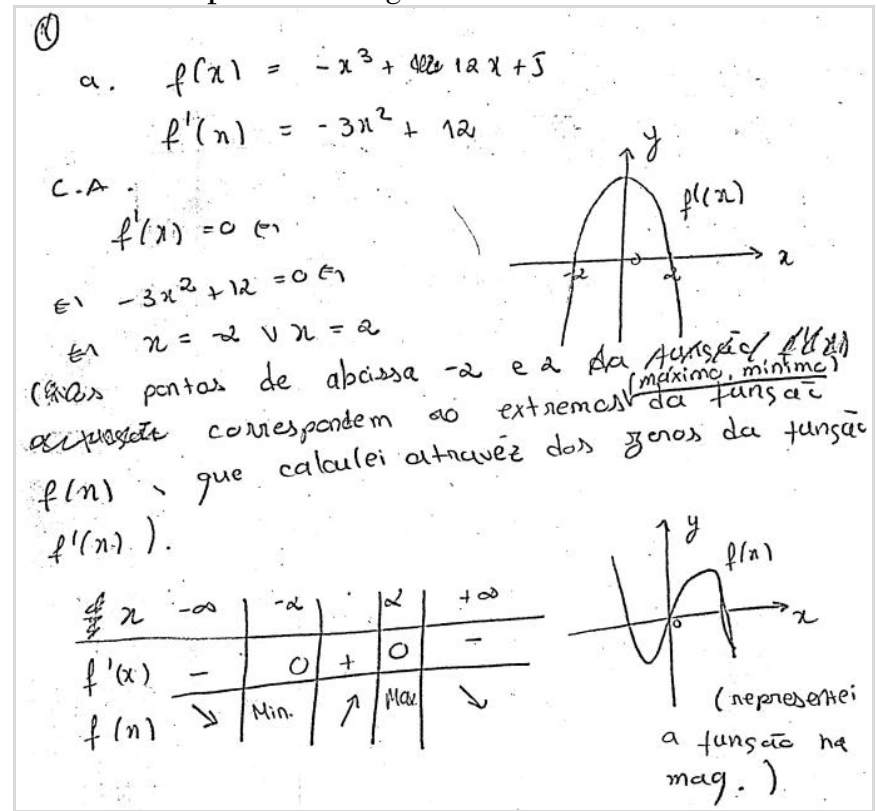

Figura 24. Resposta do aluno A8 à primeira questão da Tarefa 5.

O aluno recorre à representação gráfica como auxiliar para identificar os intervalos onde a função tem valores positivos e negativos e para representar a função e a função derivada. Utilizou a representação algébrica para derivar a função através das regras de derivação e para obter os zeros da função derivada. Por fim, construiu a tabela para o ajudar a relacionar a função e a função derivada e assim obter o máximo relativo e o mínimo relativo da função. $\mathrm{O}$ aluno utilizou a calculadora gráfica para obter a representação da função que foi utilizada para a confirmação dos extremos relativos obtidos através da representação tabelar. $\mathrm{Na}$ apresentação dos resultados o aluno não é rigoroso esquecendo-se de referir que são extremos relativos e não apenas extremos.

Outros alunos, como por exemplo o aluno A7, não recorreram à representação gráfica para os ajudar na construção da tabela.

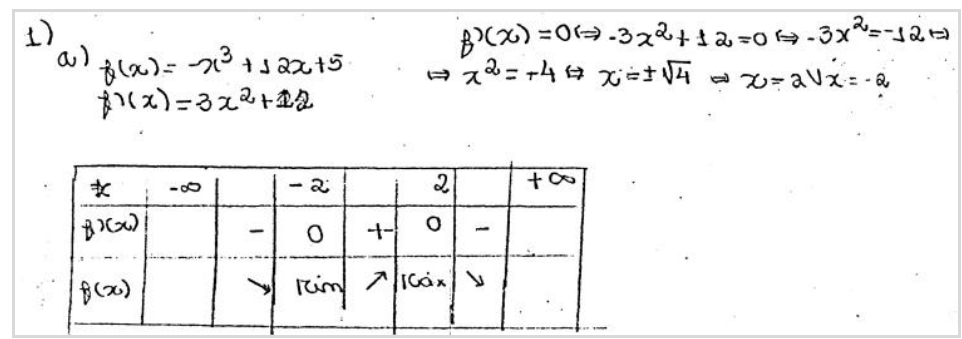

Figura 25. Resposta do aluno A7 à primeira questão da Tarefa 5.

Os alunos identificaram o intervalo onde a função é decrescente e o intervalo onde a função é crescente.

$\mathrm{Na}$ segunda questão da Tarefa 5, nenhum aluno justificou a sua resposta sobre a existência de extremos da função, como se constata na resposta do aluno A2. 
DOI: http://dx.doi.org/10.20396/zet.v25i2.8649274

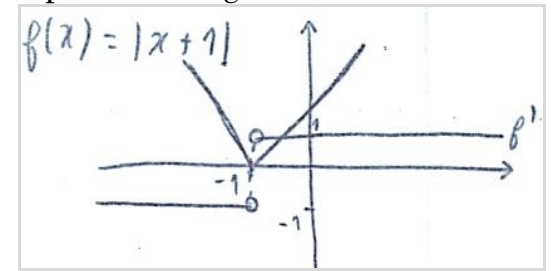

Figura 2611. Resposta do aluno A2 à segunda questão da Tarefa 5.

A maioria dos alunos tentou responder primeiro com a representação algébrica, mas, como não conseguiram, usaram a representação gráfica da função e da sua derivada com a ajuda da calculadora gráfica.

\section{Conclusões}

A análise das resoluções dos alunos às tarefas propostas permitiu inferir a forma como desenvolveram a aprendizagem da derivada de uma função com recurso a múltiplas representações. Os alunos, de um modo geral, revelaram capacidade para efetivar a conversão entre duas representações de um conceito, mas sem a garantia de que mobilizam conjuntamente os significados do conceito em causa. Utilizaram, por vezes, as diferentes representações sem estabelecer relações entre elas, realizando apenas o seu tratamento. Mas fazem sem dificuldade a codificação da informação proveniente das diversas representações (Duval, 2012). Normalmente, utilizam apenas uma representação e são raros os momentos em que os alunos utilizam mais do que uma representação em simultâneo para resolver uma questão. Os alunos tendem a repetir modos de resolução sem grande reflexão evocando apenas o conceito imagem colocando de parte o conceito definição, o que condiciona a mobilização dos seus conhecimentos para novas situações (Vinner, 2002). Embora tenham revelado preferências por métodos visuais para a compreensão dos conceitos, não revelam preferência pela utilização da representação gráfica na resolução das tarefas. Parecem entender os conceitos de modo gráfico, mas operacionalizá-los de modo algébrico.

A utilização de várias representações pelos alunos depende do tipo de questões que as tarefas contêm (Friedlander \& Tabach, 2001; Kaput, 1992). O resultado que se destacou foi o predomínio das representações numéricas, que se ficou a dever a algumas questões incentivarem a utilização dessa representação. Os alunos tendem a considerar o incentivo dado pelo tipo de questões. O facto de estarem na fase inicial da aprendizagem do tema derivada de uma função pode justificar a preferência pela representação numérica.

As representações que os alunos mobilizam no tema derivada de uma função são diversas e dependem em parte do tópico abordado. $\mathrm{O}$ uso da representação numérica surge quando a questão é considerada pelos alunos como requerendo uma resposta isolada e não como uma questão do problema inicial (Friedlander \& Tabach, 2001): quando é pedido o cálculo da taxa média de variação e a taxa de variação; quando é solicitado o preenchimento de tabelas; ou nas atividades de codificação que envolvam as representações tabelar ou gráfica. A representação gráfica foi mais usada para dar resposta às questões que poderiam ser resolvidas através do estudo comparativo da função com a sua função derivada ou no estudo da monotonia da função e extremos relativos. A representação algébrica surgiu 
DOI: http://dx.doi.org/10.20396/zet.v25i2.8649274

associada às questões que solicitavam a determinação da derivada de uma função num dado valor do seu domínio através da definição. A representação tabelar foi utilizada pelos alunos no estudo da função em determinados valores do seu domínio, estando representados na tabela, e para estudar o sinal, a monotonia e os extremos relativos de uma função, e, em alguns casos, na conversão entre a representação algébrica e gráfica. Esta representação auxiliou na obtenção da expressão algébrica no estudo introdutório da taxa de variação, devido às relações entre as variáveis tabeladas (Brown \& Mehilos, 2010).

$\mathrm{Na}$ sua maioria, os alunos tiraram conclusões sobre as tarefas propostas coordenando as diferentes representações, como foi o caso da representação algébrica com a gráfica e a tabelar com a gráfica. A representação algébrica é coordenada com a gráfica quando os alunos não conseguem resolver a questão apenas através da representação algébrica. Os alunos tentam resolver algoritmicamente as questões e só quando não o conseguem é que optam por outras alternativas que passam pela mudança de representação. As conversões não são realizadas por uma questão de escolha, mas de necessidade, sejam elas conversões congruentes ou não congruentes. Na conversão da representação algébrica para a gráfica os alunos revelaram, por vezes, não ter em atenção o contexto do problema. A representação tabelar é coordenada com a gráfica para detetar as variações na monotonia da função e identificar os extremos de uma função.

Mobilizar várias representações na mesma resolução indiciou ajudar os alunos a identificar conexões e a moverem-se de modo flexível entre diferentes representações. A capacidade de representar e identificar o mesmo conceito em diferentes representações e a estabelecer conexões permite aos alunos criar importantes analogias, desenvolver e compreender as relações/conexões entre representações. Mais importante do que utilizar várias representações é o estabelecimento de conexões entre elas (Dreyfus, 2002; Duval, 2012; Vinner, 2002). A passagem de uma representação para outra também é uma das dificuldades manifestada pelos alunos. Para Duval (2012), esta dificuldade é consequência das atividades de ensino e de aprendizagem que devem dar ênfase à exploração das conexões entre representações.

Apesar de algumas dificuldades, a maioria dos alunos conseguiu fazer a conversão das diferentes representações, o que é fundamental no processo de aquisição de conhecimento. Passar de um registo de representação para outro não é somente mudar de modo de tratamento, é também explicar as propriedades ou os aspetos diferentes de um mesmo objeto (Duval, 2012). Quando os alunos realizam conversões e consequentemente, coordenações, é porque conhecem e compreendem diferentes aspetos e propriedades do objeto matemático.

\section{Referências}

Aires, A., \& Vazquez, M. (2004). O conceito de derivada no ensino secundário ao longo do século XX. In Atas do Encontro sobre o tema História do Ensino da Matemática em Portugal (pp. 101-120). Lisboa: Sociedade portuguesa de investigação em educação matemática. 
DOI: http://dx.doi.org/10.20396/zet.v25i2.8649274

Almeida, C., \& Viseu, F. (2002). Interpretação gráfica das derivadas de uma função por professores estagiários de Matemática. Revista Portuguesa de Educação, 15(1), 193-219.

Azcárate, G., C., Casadevall, M., Casellas, E., \& Bosch, D. (1996). Cálculo diferencial e integral. Madrid: Sintesis.

Bogdan, R., \& Biklen, S. (1994). Investigação Qualitativa em Educação. Porto: Porto Editora.

Brown, S. A., \& Mehilos, M. (2010). Using tables to Bridge Arithmetic and Algebra. Mathematics Teaching in the Middle School, 15(9), 532-538.

Dick, T. P. (1996). Much more than a toy. Graphing calculators in secondary school calculus. In P. Gomez \& B. Waits (Eds.), Roles of Calculators in the Classroom (pp. 31-46). Bogata: Una Empressa Docente.

Dreyfus, T. (2002). Advanced mathematical thinking processes. In D. Tall (Ed.). Advanced mathematical thinking (pp. 25-41). Dordrecht: Kluwer Academic Publisher.

Duval, R. (2012). Registros de representação semiótica e funcionamento cognitivo do pensamento. REVEMAT, 7(2), 266-297.

Ferrini-Mundy, J., \& Lauten, D. (1994). Learning about calculus learning. The Mathematics Teacher, 87(2), 115-121.

Friedlander, A., \& Tabach, M. (2001). Promoting multiple representations in algebra. In A. A. Cuoco, \& F. R. Curcio (Eds), The roles of representation in school mathematics (pp. 173-185). Reston: VA: NCTM.

Gagatsis, A., \& Elia, I. (2004). The effects of diferente modes of representation on mathematical problema solving. In Proceedings of the 28th Conference of the International Group for the Psychology of Mathematics Education, 2, 447-454.

García, A. (2000). Nuevas tecnologías y enseñanza de las matemáticas. Madrid: Síntesis.

Giraldo, V., Carvalho, L., \& Tall, D. (2003). Descriptions and definitions in the teaching of elementary calculus. In N. A. Pateman, B.J. Dougherty, \& J. Zilliox (Eds.), Proceedings of the 27th Conference of the International Group for the Psychology of Mathematics Education, 2, 445-452.

Goldenberg, E. (1988). Mathematics, metaphors, and human factors: Mathematical, technical, and pedagogical challenges in the educational use of graphical representation of functions. Journal of Mathematical Behavior, 7, 135-173.

Goldin, G. A. (2002). Representation in mathematical learning and problem solving. In L. D. English (Ed.), Handbook of International Research in Mathematics Education (pp. $197-$ 278). Mahwah, New Jersey: Lawrence Erlbaum Associates.

Janvier, C. (1987). Representation and understanding: The notion of function as an example. In C. Janvier (Ed.), Problems of representation in the teaching and learning of 
DOI: http://dx.doi.org/10.20396/zet.v25i2.8649274

mathematics (pp. 67-72). Hillsdale, New Jersey. Lawrence Erlbaum Associates, Publishers.

Kaput, J. (1992). Technology and mathematics education. In D. Grouws (Ed.). Handbook of Research on Mathematics Teaching and Learning (pp. 515-556). New York: Macmillan.

Leinhardt, G., Zaslavsky, O., \& Stein, M. (1990). Functions, graphs, and graphing: Tasks, learning and teaching. Review of Educational Research, 60(1), 1-64.

Portugal (2014). Programa e Metas Curriculares Matemática A. Lisboa: Ministério da Educação e Ciência.

NCTM (2008). Princípios e Normas para a Matemática Escolar. Lisboa: APM.

Ponte, J., \& Canavarro, A. (1997). Matemática e Novas Tecnologias. Lisboa: Universidade Aberta.

Ruthven, K. (1993). Personal Technology and Classroom Change: A British Perspective. In J. T. Fey (Ed.), Calculators in mathematics education (pp. 91-100). Reston: National Council of Teachers of Mathematics. (Yearbook 1992).

Tall, D. (1994). Computer environments for the learning of mathematics. In R. Biehler, R. W. Scholz, R. Sträßer \& B. Winkelmann (Eds.), Didactics of mathematics as a scientific discipline (pp. 189-199). Dordrecht: Kluwer Academic Publisher.

Tall, D. (2002). The psychology of advanced mathematical thinking. In D. Tall (Ed.). Advanced mathematical thinking (pp. 3-21). Dordrecht. Kluwer Academic Publisher.

Teixeira, P., Precatado, A., Albuquerque, C., Antunes, C., \& Nápoles, S. M. (1998). Matemática: funções - $11^{\circ}$ ano de escolaridade. Lisboa: Ministério da Educação, Departamento do Ensino Secundário.

Vinner, S. (1983). Conflicts between definitions and intuitions: the case of the tangent. In Proceedings of the 6th PME Conference, Antwerp. (pp. 24-28).

Vinner, S. (1989). The avoidance of visual considerations in calculus students. In T. Eisenberg \& T. Dreyfus (Eds.), Focus on Learning Problems in Mathematics, 11(2), 149-156.

Vinner, S. (2002). The role of definitions in the teaching and learning of mathematics. In D. Tall (Ed.). Advanced mathematical thinking (pp. 65-81). Dordrecht. Kluwer Academic Publisher. 